This item was submitted to Loughborough's Research Repository by the author.

Items in Figshare are protected by copyright, with all rights reserved, unless otherwise indicated.

\title{
Contextual factors influencing decision making: Perceptions of professional soccer players
}

\section{PLEASE CITE THE PUBLISHED VERSION}

https://doi.org/10.1016/j.psychsport.2018.04.001

\section{PUBLISHER}

(c) Elsevier

\section{VERSION}

AM (Accepted Manuscript)

\section{PUBLISHER STATEMENT}

This paper was accepted for publication in the journal Psychology of Sport and Exercise and the definitive published version is available at https://doi.org/10.1016/j.psychsport.2018.04.001

\section{LICENCE}

CC BY-NC-ND 4.0

\section{REPOSITORY RECORD}

Levi, Hannah R., and Robin Jackson. 2019. "Contextual Factors Influencing Decision Making: Perceptions of Professional Soccer Players”. figshare. https://hdl.handle.net/2134/32726. 


\section{Accepted Manuscript}

Contextual factors influencing decision making: Perceptions of professional soccer players

Hannah R. Levi, Robin C. Jackson

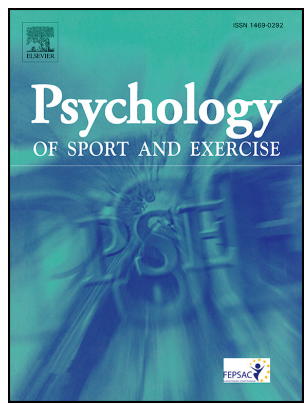

PII: S1469-0292(17)30504-6

DOI: $\quad$ 10.1016/j.psychsport.2018.04.001

Reference: PSYSPO 1346

To appear in: Psychology of Sport \& Exercise

Received Date: 26 July 2017

Revised Date: 6 April 2018

Accepted Date: 6 April 2018

Please cite this article as: Levi, H.R., Jackson, R.C., Contextual factors influencing decision making: Perceptions of professional soccer players, Psychology of Sport \& Exercise (2018), doi: 10.1016/ j.psychsport.2018.04.001.

This is a PDF file of an unedited manuscript that has been accepted for publication. As a service to our customers we are providing this early version of the manuscript. The manuscript will undergo copyediting, typesetting, and review of the resulting proof before it is published in its final form. Please note that during the production process errors may be discovered which could affect the content, and all legal disclaimers that apply to the journal pertain. 
Running head: CONTEXTUAL FACTORS INFLUENCING DECISION MAKING

Contextual Factors Influencing Decision Making: Perceptions of Professional Soccer Players

Hannah R. Levi

School of Sport, Exercise and Health Sciences, Loughborough University ${ }^{1}$, UK

$\&$

Robin C. Jackson

School of Sport, Exercise and Health Sciences, Loughborough University, UK

${ }^{1}$ Present Address: $\quad$ School of Sport, Health and Applied Science, St Mary’s University, UK

Corresponding author: Hannah Levi

School of Sport, Health and Applied Science

St Mary's University

Strawberry Hill

Twickenham, UK

TW1 4SX

Tel: $\quad+44(0) 7530925323$

Email: 166925@live.stmarys.ac.uk 
Contextual Factors Influencing Decision Making: Perceptions of Professional Soccer Players

\begin{abstract}
Objectives: This study sought to explore highly-skilled soccer players' perceptions of how contextual factors influence their decision making during matches.

Design: A qualitative design was used in which individual semi-structured interviews were conducted with eight professional male soccer players aged between 18 and 22 years.

Method: An interview schedule was designed to explore the perceived influence of a range of situational factors on decision making during matches. The interviews were recorded and transcribed verbatim. The data were analysed via an inductive thematic analysis.
\end{abstract}

Results: Seven themes were identified from the data. The four dynamic contextual themes were: (a) personal performance, (b) score status, (c) momentum, and (d) external/coach instructions. The three static contextual themes were: (a) match importance, (b) personal pressures, and (c) preparation.

Conclusions: The results highlight the importance of considering the dynamic and static context within which highly-skilled soccer players make decisions.

Keywords: context, decision making, soccer 
1

2 Running head: CONTEXTUAL FACTORS INFLUENCING DECISION MAKING

3

4

5

6

7 Contextual Factors Influencing Decision Making: Perceptions of Professional Soccer Players

8

9

10

11

12

13

14

15

16

17

18

19

20

21

22

23

24 
Abstract

26 Objectives: This study sought to explore highly-skilled soccer players' perceptions of how

27 contextual factors influence their decision making during matches.

28 Design: A qualitative design was used in which individual semi-structured interviews were

29 conducted with eight professional male soccer players aged between 18 and 22 years.

30 Method: An interview schedule was designed to explore the perceived influence of a range of

31 situational factors on decision making during matches. The interviews were recorded and

32 transcribed verbatim. The data were analysed via an inductive thematic analysis.

33 Results: Seven themes were identified from the data. The four dynamic contextual themes

34 were: (a) personal performance, (b) score status, (c) momentum, and (d) external/coach

35 instructions. The three static contextual themes were: (a) match importance, (b) personal

36 pressures, and (c) preparation.

37 Conclusions: The results highlight the importance of considering the dynamic and static

38 context within which highly-skilled soccer players make decisions.

39

40 Keywords: context, decision making, soccer 
Contextual Factors Influencing Decision Making: Perceptions of Professional Soccer Players

1. Introduction

skilled performers often required to make the right decision under extreme time pressures

(Kinrade, Jackson, \& Ashford, 2015). Given the dynamic and complex sport environment, which involves myriad decisions, researchers have focused on various aspects of the decision-making process (Macquet, 2009) and have predominantly used a reductionist approach to examine selected aspects of perceptual-cognitive expertise, prioritising experimental control over ecological validity (Williams, 2009). Research in other timeconstrained settings, such as with chess players (Chase \& Simon, 1973) and medical experts (Verkoeijen, Rikers, Schmidt, van de Wiel, \& Kooman, 2004), suggests that context is critical in assisting high-quality decisions. However, given the tighter focus required in experimentally-controlled designs, sport-specific studies have not considered the contextual complexity of typical match situations (Schlappi-Lienhard \& Hossner, 2015).

With such unpredictability in sport, it has been suggested that researchers would benefit from going beyond examining individual perceptual-cognitive factors that guide performers' decisions by considering the behavioural interaction between performers and the real-life sport environment (Davids \& Araújo, 2010; Travassos et al., 2013). In beginning to address this shortcoming, the aim of the present study is to examine soccer players' perceptions of how contextual factors influence their in-match decision making. In the present study, 'context' is defined as "the circumstances that form the setting for an event" (Oxford English Dictionary, 2018), in this case, circumstances before and during a match that influence decision making. Accordingly, it allows players to consider a broader range of environmental and personal factors than have typically been considered in studies of anticipation skill. 


\subsection{Decision Making Research from an Experimental Perspective}

Since the work of Starkes and Deakin (1984), experimental research has revealed

differences in the nature and type of decisions involved in sport (Bar-Eli \& Raab, 2009). A number of researchers have applied the expert performance paradigm to sport, commonly using sport-specific film simulations to assess decision accuracy, response time and movement-based responses alongside process-tracing measures such as eye movement analyses and verbal reports (Ericsson \& Ward, 2007). This has led to significant progress in identifying factors that contribute to successful decision making. For example, in soccer, superior performance was found to be characterised by faster decision times and greater response accuracy, underpinned by successful decision makers using more goal-orientated search strategies than their less successful counterparts (Vaeyens, Lenoir, Williams, \& Philippaerts, 2007). Other researchers found that skilled soccer players made more fixations of shorter duration to more locations than less-skilled players when making decisions (Roca, Ford, McRobert, \& Williams, 2013). In the task, players observed simulated match sequences filmed from the perspective of a central defender. In a second experiment, analysis of verbal protocols revealed that the more skilled players made more cognitive statements on each trial, reflecting greater domain-specific knowledge.

Sport-specific film simulation research has enhanced our knowledge of some of the processes underlying superior decision making; however, there has been relatively little progress made in understanding the role of contextual factors. The importance of context was evident in a study by McRobert, Ward, Eccles, and Williams (2011), who manipulated the information available to cricket batters. Skilled and less-skilled performers responded to video simulations of opponents bowling a cricket ball under low (24 balls from six bowlers, presented in random order) and high ( 24 balls from four bowlers, presented in six consecutive balls from each bowler) context conditions. The study revealed that skilled batters were more 
91

92

93

94

95

96

97

98

99

100

101

102

103

104

105

106

107

108

109

110

111

112

113

114

115

accurate during the high-context condition compared to less-skilled batters, suggesting that the additional context allowed players to extract information from the relevant location more

efficiently. Other contextual factors such as court position, shot sequencing, (Abernethy, Gill,

Parks, \& Packer, 2001; Murphy, Jackson, Cooke, Roca, Benguigui, \& Williams, 2016), and inferred probability information (Gray, 2002a; Paull \& Glencross, 1997) have also been

found to aid judgment accuracy. Conversely, researchers have shown that response time, response accuracy, or response timing may be impaired when action outcomes are incongruent with expectations arising from contextual information, such as situational probability information (Barton, Jackson, \& Bishop, 2013), baseball pitch count (Gray, 2002b), and sequencing of volleyball shorts (Loffing, Stern, \& Hagemann, 2015). These

findings provide preliminary support for the value of exploring other contextual factors that may be involved in sport-specific decision making. While research using sport-specific film simulations has progressed our knowledge of aspects of superior decision making, research of this nature lacks ecological validity in that it tends to focus on a small number of predetermined contextual factors, thereby limiting our understanding of real-life sport decisions. 1.2 Toward a more Naturalistic Approach to Understanding Decision Making One method employed to enhance ecological validity in the study of decision making is 'naturalistic decision making' (NDM), which centres around decisions made in natural situations (Schläppi-Lienhard \& Hossner, 2015). NDM research considers complex, realworld settings that acknowledge the dynamic and uncertain conditions and real-time reactions to these uncertainties. NDM studies have investigated decision making in various highpressure fields such as firefighting, nuclear power plants, aviation, military, paramedics and sport (Macquet, 2009). In sport, the primary method of data collection is self-confrontation interviews, in which each participant is confronted with a video of themselves playing in a real match and is asked to "think aloud" (Macquet, 2009). Unlike laboratory studies using 
film simulations, which require immediate responses to an observed scenario, self-

117 confrontation interviews do not involve actively making any decisions, but rather focus on a

118 discussion around previously made decisions. The idea is to elicit concurrent cognitions and

119 salient features considered by the players during their own real-life impromptu match

120 decisions (Hoffman, Shadbolt, Burton, \& Klein, 1995).

121 NDM research in the sport domain has revealed the significance of match-specific

122 contextual factors. One study revealed that expert badminton players only tried to finish a

123 point when situational conditions of the rally were perceived to be favourable to winning the

124 point (Macquet \& Fleurance, 2007). More broadly, the players expressed that their intentions

125 and decisions reflected the contextual development of a rally and that their situational

126 understanding was informed by past events and current player competencies. Macquet and

127 Kragba's (2015) study of basketball players produced analogous findings, in which the

128 players revealed that they considered teammates' and opponents' placements, moves, and

129 actions, when assessing the situation and anticipating how the situation would develop.

130 Similarly, a study of handball players illustrated that decision making relied, at least in part,

131 on situational progression of the match (Lenzen, Theunissen, \& Cloes, 2009). More

132 specifically, the players' verbal reports suggested that their decision making involved

133 perception, knowledge, expectations, and contextual elements, demonstrating the influence of

134 dynamic contextual factors on the players' decisions. While extant literature has highlighted

135 the value of considering individual contextual factors when exploring decision making in

136 sport, the research remains limited in its ability to capture the full complexity of contextual

137 influences (McRobert et al., 2011).

$138 \quad 1.3$ Study Objective

139 Overall, while the NDM research has made progress in understanding the role of

140 contextual information and its interaction with perceptual-cognitive processes in sport, there 
141 appears to be a narrow focus of self-confrontation interviews as the method for data

142 collection. In self-confrontation interviews, the performer is restricted to deliberating on

143 specific decisions made within the particular context of a single match. This method,

144 therefore, does not allow for a broader consideration of the types of decisions made in sport

145 and the perceived importance of contextual factors. In an effort to capture a wider array of

146 contextual factors involved in decision making in top-level soccer, the present study

147 employed semi-structured interviews to examine professional players' perceptions of how

148 contextual factors influence their decision making. Semi-structured interviews allow

149 performers to organically recognise salient contextual factors and their influence on the types

150 of decisions made in soccer more generally, without limitation of discussion around decisions

151 made in a single match. Accordingly, the objective of the study was to identify contextual

152 factors the players perceived to be important and how they influence the decision-making

153 process.

\section{Method}

\subsection{Participants}

Eight male professional soccer players participated in the study. The participants had a mean age of 19.0 years $(S D=1.4$, range $=4.0)$, had been competing at the professional level for a mean of 2.0 years $(S D=1.9)$, and included two defenders, four midfielders, and two attackers.

2.2 Recruitment

Following approval from the University's Ethical Approval Committee, purposive sampling was used to recruit elite level participants from a highly successful English Premier League Soccer Academy Under-23 team. The participants were initially informed about the nature and purpose of the study by their coach and those who expressed an interest in

165 participating were then scheduled to meet with the researcher. More specific details of the 
166

167

168

169

170

171

172

173

174

175

176

177

178

179

180

181

182

183

184

185

186

187

188

189

190

research study were then given to participants and interviews were scheduled with those who agreed to participate.

\subsection{Interview Guide}

To gather relevant data, a semi-structured interview guide was developed in accordance with the principles set out by Braun and Clarke (2006). The interview guide was then checked and modified following a pilot interview, which highlighted the need to rephrase and reorder some of the questions.

The interview guide opened with questions about the participant's decision making associated with their playing position, then targeted contextual factors relating to coach instructions before and during a match, perceived personal, own team, and opposing team strengths and weaknesses, the referee, and a range of specific situational factors. There was a question regarding the extent to which training took into account the contextual factors discussed before ending with giving the participants an opportunity to share any additional contextual factors they believe impact their decision making. Sample questions included: "can you describe the decision making part of playing in your position?", "to what extent do you think instructions given to you during a match influence your decision making?", and "is there anything else that you would like to add that you think influences your decisions during matches?".

While the broad structure of the interview was the same for all participants, the order of questions was dependent on participants' responses. The interviewer always started by asking for an example of a decision-making scenario from a match to get the participant thinking about specific match situations. After the first example, the interviewer asked for additional examples whenever contextual factors were reported to affect decision making. Impromptu clarification and elaboration probes were used throughout the interview. For example, questions such as, "in what way?", and "can you give me an example?" were used 
191

192

193

194

195

196

197

198

199

200

201

202

203

204

205

206

207

208

209

210

211

212

213

214

215

to gain further insight into how a contextual factor influenced their decision making. Thus,

while the interview was structured around broad contextual themes, there was scope for exploring in more depth those deemed to have an effect on decision making, for example,

through use of elaboration probes.

\subsection{Data Collection Procedure}

Prior to their interview, each participant was given a written and verbal description of the study and its objectives. Each participant was made aware that all the information they shared would remain confidential, would be used solely for the purpose of the study, and that only a generic and anonymous summary of potential practical implications arising from the study would be made available to their coaches. They then signed a consent form and completed a participant information form.

The interviews were conducted in a quiet room on the soccer academy premises for participant convenience. All interviews were scheduled either prior to or following a training session and lasted between 26 and 43 minutes ( $M=35.91$ minutes, $S D=6.74$ minutes). The interviews were not conducted under time pressure and therefore none had to be aborted.

A semi-structured interview is often more conversational than a strictly structured interview (Smith, 1995); therefore, the contextual factors that were most salient to participants became apparent through discussion. This flexible approach allowed for unexpected findings to emerge since participants were encouraged to discuss contextual factors unconstrained by pre-determined questions. The interviewer had competed in soccer at a professional level and therefore possessed contextual knowledge and understanding of the sport-specific terminology. Consequently, the interviewer did not have to ask for additional clarification questions about use of 'jargon', which facilitated the development of good rapport and ease of conversation with the participants.

2.5 Data Analysis 
Each interview was recorded and transcribed verbatim. To ensure confidentiality and

217

218

219

anonymity throughout the analytic process, pseudonyms were assigned to each participant.

The interviews were read twice in order to fully immerse the researcher in the transcripts. The data were then analysed using an inductive thematic analysis. This method generates an analysis from the data itself (i.e., inductive) and is therefore not constrained by pre-existing theory (Braun \& Clarke, 2006).

The analysis followed a recursive process based on the six phases developed by Braun and Clarke (2006). The first phase involved becoming familiar with the data through transcription, preliminary readings, and making note of initial observations and ideas. The second phase entailed a process of complete coding in which features related to the influence of contextual factors on decision making were coded across the entire data set and then collated. In the third and fourth phase, the relevant codes were organised into potential related yet distinct themes, which were then cross-checked with the coded extracts and full data set and finally generated into a thematic 'map' of the analysis. The process of creating a thematic 'map' comprised of combining the first and second-order themes into suitable groups. The next stage consisted of an ongoing analysis to refine the detailed features of each theme, along with finalising clear definitions and names for each. The sixth and final phase required producing the written report through a selection of apt and compelling extract examples that relate the analysis to the research question and appropriate literature.

\section{Results and Discussion}

Given the contention surrounding what constitutes validity in qualitative inquiry, this study is in accordance with the eight key criteria proposed by Tracy (2010): worthy topic, rich rigor, sincerity, credibility, resonance, significant contribution, ethics, and meaningful coherence. From the data, seven contextual themes emerged that were perceived as having an influence on the players' decision making. These were grouped under two higher-order 
241 themes according to their static or dynamic nature. The four dynamic contextual themes

242

243

244 were: personal performance, score status, momentum, and external/coach instructions. The three static contextual themes were: match importance, personal pressures, and preparation.

\subsection{Dynamic themes}

The players revealed that their decisions on the pitch relied on the situational development, or in other words, the dynamic nature of the match. More specifically, participants suggested that certain dynamic contextual factors, such as positive perceptions of their performance, a winning score status, and positive momentum resulted in more confident decision making, which was often characterised by experimental or risky decisions. The players also suggested that in certain contexts within a match, instructions from their coach were valued while in others they could hinder the decision making process. This reveals how the transient and dynamic nature of the match impacts the internal psychological process through which players make decisions.

\subsubsection{Personal performance. Every player highlighted that their perceptions of} personal performance during a match impacted the decisions they made. More specifically, their own performance was a key source of confidence for the players, with high confidence leading to more adventurous decision making and low confidence leading to more conservative decision making:

With me, if I'm like playing well, I'll try anything, so like, it's more of a confidence thing, like, if when the ball comes to me, the first thing I normally try and do is 'right get a safe pass off' and then build from there. And then if I'm having a bad game, I think 'right I'm just gonna play safe' so it would effect my decisions... but if I'm having like a really good game then my confidence goes up and I'll just try anything. (Matt) 
All of the participants spoke about how their confidence increased throughout the

266

267

268

269

match when they were playing well, which progressively increased their willingness to make more risky decisions. Moreover, some players suggested that the first five or ten minutes of a match were disproportionately important for building confidence. For example, when talking about making more risky decisions, one player expressed:

I think what does have an effect, say your first five minutes of a game or your first ten minutes if you're playing well then... I would say more importance on the start of the game than necessarily previous games or training sessions. (Henry)

It is evident that a large part of confident decision making during a match was dependent on their performance on the day. Whether it be through the first five or 10 minutes or throughout the entire match this aligns with Bandura's (1997) self-efficacy theory, specifically the prediction that performance accomplishments will elicit the most potent effects upon self-efficacy. While the participants used the term 'confidence', their comments also highlight the situational and time-specific nature of their self-efficacy in regard to decision making.

3.1.2 Score Status. The participants identified that score status often impacts the types and emotional valence of decisions they make throughout a match. More specifically, they identified being in a winning position as a prominent determinant of making more confident decisions, while being in a losing position was recognised as a basis for more communication to guide their decisions. For example, John exclaimed, "when we're winning I feel confident in my decisions", while another player highlighted the link between winning, confidence and effective decision making:

Simon: If you're winning I think you're probably naturally making better decisions. Interviewer: Why? Why do you think that? Simon: Erm confidence. 
confident decisions. This is consistent with previous research in which winning was found to

292

293 significantly predict confidence in males (Jones, Swain, \& Cale, 1991) and that, in

comparison to females, male performers place a greater emphasis on winning, beating others, and successful competition outcomes (Hays, Maynard, Thomas, \& Bawden, 2007). While it is beneficial for performers to gain confidence from taking the lead during a match, the fact that confident decision making is so reliant on the scoreline again highlights its potentially

transient nature. Sensitivity to the context in which one is performing is clearly important; however, there appears significant scope for developing decision-making skills that are more robust and resilient to the situational context.

When confronted with a situation in which the team was losing, the players revealed that they had a greater inclination to allow others to guide their decisions. Whether from teammates or coaches, communication was considered fundamental to avoid conceding more goals:

If we're losing of course, and they wanna switch it around and start pressing the ball back and going to score, then it's vital we listen, there is communication, 'cause if no one's talking then we probably concede more and more goals. (Brad)

When a team is losing, or feeling a lack of control of the game, it is reasonable to want to change the tactics or style of play and these comments reflect the perceived importance of communication in ensuring this is done cohesively (Carron, Colman, Wheeler, \& Stevens, 2002). There is mixed evidence regarding the relationship between score status and frequency of communication. In a study of netball, researchers found that more frequent on-court talk was associated with less-successful outcomes (LeCouteur \& Feo, 2011).

Conversely, in a study of tennis, winning doubles pairs exchanged twice as many messages as losing teams (Lausic, Tenebaum, Eccles, Jeong, \& Johnson, 2009). The present interviews 
315

316

317

318

319

320

321

322

323

324

326

327

suggest that increased communication between players is simply a response to tactical changes resulting from score status, and this is perceived to be beneficial.

3.1.3 Momentum. Another dynamic situational factor that affected the players'

decision making was momentum, which was described as a period during which one team had large amounts of possession and/or instigated repeated attacking play. Despite the feeling of momentum usually only lasting a few minutes in a match, it appeared that this was sufficient to influence the confidence of players' decision making. For example, one player said, "I think, well, when you have momentum you have more confidence" (Craig). Despite limited research in this area, this finding is consistent with the reconceptualised model of sport confidence in which situational favourableness was identified as a salient source of confidence for athletes (Vealey, Hayashi, Garner-Holman, \& Giacobbi, 1998). Situational favourableness represents the idea that performers gain confidence in situations where they feel the breaks are in their favour. Interestingly, such favourableness is apparent regardless of the score, suggesting an alternative, if somewhat unreliable, source of decision making confidence.

In light of the quotes that suggest confidence is generated through momentum, it is perhaps unsurprising that when momentum was not in their favour, players made lessconfident decisions or employed a more conservative decision making strategy to try to counteract momentum:

If you [are] against it, against momentum, I think it's quite difficult. You gotta do like the basic things right and not take risks. You just gotta try and keep it simple and just do all the basic things properly just to get that bit of pressure and momentum off you a little bit and try and lift your team up. (Scott) While Scott did not explicitly acknowledge a lack of confidence when momentum was against his team, he referred to the importance of 'keeping it simple', in contrast to the 
more risky or low-probability decisions the players identified as making when confident. This

is an apt example of the powerful yet transient influence of context on decision making. A

342 contextual factor, momentum, over which players perceived that they had little control and

343 that lasted only a few minutes, nonetheless resulted in strategic deployment of a more risk-

344 averse and interactive decision making strategy. Rather than trying to score a goal, the

345 primary concern of players shifted to low-risk decisions, the outcomes of which were more

346 assured. Previous decision-making research in soccer has primarily focused on offensive

347 scenarios; however, the value attached to more conservative decision making in certain match

348 situations highlights the importance of considering the context in which decisions are made to

349 develop a more comprehensive understanding of in-event decision making. In certain

350 contexts, decisions that lead to a goal-scoring opportunity would not necessarily be considered superior, as has been assumed in more offence-focused studies (Roca et al., 2013; Vaeyens et al., 2007). were certain contexts in which coach instructions were valued and others where they were considered potentially detrimental to decision making. For example, when the players were given advice while they were in possession of the ball, they felt this interfered with the fluency of their decision-making process:

I don't like it when I'm playing football and especially, you know, like, if you play right or left back, you're right by the touchline and sometimes if you're right by the dug out, you get the ball at your feet and someone will go 'ah give it to Joe' and in my head I'm already thinking I'm gonna pass it to someone else, then I'm like 'ooh', so I don't like it when they say something. I'd rather just in the moment, I'd rather I just 
Some of the players articulated how they often made decisions before receiving the

365

366

367

368

369

370

371

372

374

375

376

377

378

379

380

381

382

383

384

385

386

387

ball so when they were given instructions after gaining possession of the ball the decision-

making process was more challenging. These players expressed negative reactions caused by

ill-timed instructions, noting how they can "put you off your game" (John) and "I wouldn't

say confuse I would say if anything maybe annoyed" (Henry). The danger with triggering

'reinvestment' of explicit processes is well established in the motor skill literature and similar

individual difference factors have been identified in decision making (Kinrade et al., 2015).

Accordingly, the role of in-event instructions in triggering these processes warrants further investigation.

In certain contexts such as in areas of perceived weakness, or following poor decisions, the participants expressed a preference for guidance on decision making. For example, one player articulated the importance of listening to advice after making an error: If you made a mistake and they're trying to tell you to do it differently and that will help you not make a mistake, then yeah, you should listen to what they're saying a hundred per cent. (Simon)

This was reflected in position-specific preferences, in which attacking players expressed a stronger preference for in-match instructions from their coach for defensive decisions, in contrast to preferring more freedom to make decisions in attacking decisionmaking situations. The reverse was true for defensive players. Taken together, this indicates situation-specific expertise is an important contextual factor that influences the decisionmaking process, even within a group who are highly skilled. This is reflected in a preference for using personal judgement in areas of perceived proficiency, and for seeking guidance in situations of perceived weakness. This is consistent with a recent study in Australian-rules football, which showed that experienced players relied more on their "know-how" to guide their decisions, whereas less-experienced players were more likely to adhere to coach 
instructions (Buszard, Farrow, \& Kemp, 2013). By implication, coaches and managers may benefit from prioritising in-match instructions regarding areas of perceived weakness in their

391 players.

\subsection{Static themes}

During the interviews the participants revealed that to understand in-event decision making, one must also look beyond the dynamic context of the match to that of more external, or static contextual factors. The participants recognised that contextual factors that did not change throughout the match, such as the match importance, personal pressures, and preparation, contributed to the decisions they made on the pitch. More specifically, whether in response to the importance of a match or personal incentives to play well, the players suggested that perceived pressure sometimes impaired the spontaneity or fluency of their decision making. Furthermore, players' perceptions of how they had prepared for the match influenced the decisions they made on the day.

3.2.1 Match importance. In addition to the contextual factors that develop during a match the participants suggested that the broader significance of the match also influences their decision making on the pitch. There was considerable variability in the amount of pressure perceived by the participants and the extent to which this was affected by the importance of the match. Indeed, one participant described being indifferent to the significance of the match, going as far as to say, "yeah for sure I don't feel the pressure"

408 (John), while another participant was clear that match importance had adversely affected his 409 decision making: decisions because you're, you wanna score so much that you actually make the wrong one a couple of times. (Henry) 
This participant revealed that perceived pressure led to more direct, rushed, and even

414 rash decisions. In contrast to the effect of coach instructions that may confuse and slow down

415 the decision-making process, the comments are more consistent with attention control theory,

416 in particular with reduced inhibition of responses and greater influence of the stimulus-driven

417 attentional system (Eysenck, Derakshan, Santos, \& Calvo, 2007).

418 Variability in reactions to match significance reflects evidence supporting the

419 importance of individual difference factors in responses to pressure situations. For example,

420 trait activation theory predicts that specific trait-relevant situational cues trigger behavioural

421 responses to situations (Tett \& Guterman, 2000), while other researchers have identified an

422 inverse relationship between neuroticism and performance under pressure in decision making

423 scenarios (Byrne, Silasi-Mansat, \& Worthy, 2015). Individual differences in the propensity

424 for reinvesting conscious control and ruminating over past poor decisions are also strong

425 predictors of poor decision making under pressure in sport (Jackson, Kinrade, Hicks, \&

426 Wills, 2013; Kinrade et al., 2015). The implication of this is that a full understanding of

427 decision making requires consideration of both the external and internal context in which

428 situations are experienced and decisions made. More detailed knowledge of these

429 relationships should lead to practical benefits in terms of individualised preparation for

430 important events.

431 3.2.2 Personal pressures. During the interviews, the participants were invited to

432 identify additional sources of pressure they believed influenced their decision making. At this

433 stage a number of sources of perceived pressure were revealed as having the potential to

434 impact on-field decision making. For example, one player referred to the on-going pressure

435 associated with regularly competing at this level, stating, "in football there's always

436 something at stake" (Craig). Contractual status was also identified as an additional influence

437 and potential source of pressure: 
If you're on the verge of getting a new contract you want to give yourself the best negotiation cards that you can have then you get pressure from that... because you're playing on maybe two-year contracts one-year contracts three-year contracts so your future is as much as you're playing for that game you're also playing for the next game so staying in the team is one thing. (Craig)

Researchers have identified a range of internal and external sources of perceived pressure (Rushall \& Sherman, 1987) and these examples highlight the broader competitive and organisational context in which players perform. The effect of additional sources of pressure on decision making has been established in other domains such as public health (Zardo, Collie, \& Livingstone, 2014) but is yet to be systematically examined in more timeconstrained decision making such as those found in sports and therefore warrants further investigation.

3.2.3 Preparation. The players' responses throughout the interviews suggested that their perceptions of how well they had prepared for a specific match influenced their decision making on the pitch. Training sessions that focused on decision making were considered an important determinant of in-match decision making; indeed, one player suggested that training was the most influential factor, "I think game-based [training] is a massive, has a massive effect on how good or bad your decision making is... I would argue potentially the biggest [influence]" (Henry). Despite all the participants recognising the significance of their practices on their decision making, there was considerable variation in their proposed rationales for why such preparation was so influential.

The idea of creating habits through practice surfaced as one explanation, "you try to do obviously, the things you wouldn't do in a match, in training, so you can get used to them and create habits and just goes on to the pitch with you as well” (Brad). Another player expressed the importance of replicating situations that are likely to occur in the match: 
463

464

465

466

467

468

469

470

471

472

473

474

475

476

477

478

479

480

481

482

483

484

485

486

487

I find football personally like a memory thing, like if you can, if your brain can realise that you've been in this situation before, you will be able to get out of it... so I think in training if you're doing something and it comes up in a game you'll know exactly what to do because it's a memory thing. (Simon)

Pattern recognition, visual search, and associated thought processes are important determinants of decision-making proficiency (Roca et al., 2013) and participants revealed this was explicitly reflected in scenarios enacted during training sessions. It was also

acknowledged that the training sessions during the week leading up to each match were particularly powerful in relation to decision making on the pitch. One player noted that the recency of training may impact his decisions, "because if you [have] been doing it all week so that would probably play on your mind so I think it could change the decisions you make" (Scott). Another player also fixated on the week of training between matches, suggesting that the focus on the upcoming opponent was pivotal to the success of in-event decision making: The last match we did practice the day before the game and it was, we were walking through ways of or to defend against a team, so the team that we played like to pass the ball a lot and try to go through the third to play, so we tried to make the pitches as small as possible so they go around instead of through us. (John)

In regard to time-pressured decision making, the Take the First (TTF) heuristic predicts that when confronted with familiar, yet ill-defined tasks, performers generate only a very small number of options and tend to choose the first option that comes to mind (Johnson \& Raab, 2003). Raab and Laborde (2011) found that higher-skilled handball players generated fewer options than less-skilled players and that the number of options generated was negatively correlated with decision quality. Viewed through this lens, the training sessions leading up to a match can be seen as 'contextual preparation', in which knowledge of the opposing team's strengths, weaknesses, and tactical preferences are used to sensitise 
players to the formations they are likely to experience and constrain the decision options they

489

490

491

492

493

494

495

496

497

498

499

500

501

502

503

504

505

506

507

508

509

510

511

512

might generate, resulting in faster and better decisions (Helper \& Feltz, 2012). Accordingly,

TTF heuristic offers a potential conceptual framework for guiding how performance analysis data is used to enhance in-match decision making.

\section{Conclusion}

In the present study we sought to identify contextual factors that professional soccer players perceive to be important in influencing their decision making during a match. In light of the broad nature of the research question, semi-structured interviews were conducted as they allow for a general consideration of the types of contextual factors involved in decision making without restriction of decisions made in one match, as is the case in selfconfrontation interviews. Nonetheless, it is important to acknowledge that in designing the semi-structured interview protocol, a range of contextual factors were specified and these may have affected the responses of participants. In particular, while great care was taken to ensure individual questions were not leading, the very fact that a contextual theme was mentioned may have increased participants' perceptions of its importance. To counteract this, care was taken to ensure questions were frames neutrally and elaboration probes were only used when participants indicted that a contextual factor affected decision making in some way.

The present study revealed that soccer players' decisions on the pitch rely on both the situational development of the match (i.e. dynamic themes) and the broader external context of the match (i.e. static themes). Consistent with previous research highlighting the importance of situational determinants of decision making (Lenzen et al., 2009; Macquet \& Fleurance, 2007; Macquet \& Kragba, 2015), the present study revealed that in-match factors such as perceptions of performance, a winning score status, and momentum were perceived to have a significant influence on the players' ability to make more confident decisions. The 
513 players also suggested that instructions from their coach during a match were sometimes

514 valuable (e.g., guidance following poor decisions), and at other times a hindrance (e.g., when

515 in possession of the ball) on their decision making process. Furthermore, the present study is

516 the first to provide (qualitative) data concerning the impact of broader static contextual

517 factors on soccer players' decision making. More specifically, the participants suggested that

518 the importance of a match and personal incentives to play well sometimes impaired the

519 spontaneity or fluency of their decision making. They also revealed that they perceived

520 training sessions in the days leading up to a match to be critical for providing a match

521 specific context that facilitated effective decision making in the match itself.

522 It is important to remain cognisant that this study merely sought to explore and

523 identify the broad array of contextual factors that influence soccer players' decision making.

524 The broad scope of the study meant that it was impossible to establish the specific way that

525 such factors combine to influence decisions, but we suggest this should be addressed in future

526 studies. Likewise the study sample contained only male soccer players from one academy, so

527 it is possible that players from a different demographic (e.g., age group, gender, culture) will

528 identify additional contextual factors. Furthermore, it is likely that both the contextual factors

529 and their influence on decision making changes during skill development. Large-scale cohort

530 designs and longitudinal research will further develop knowledge in this area. A further

531 limitation of the study is that it relied on the accuracy of the participants' recall, together with

532 their ability and willingness to articulate their experiences. Whilst the quality and depth of the

533 responses provided would suggest these were not serious problems, they must be considered

534 in evaluating the findings of the study.

535 The present findings highlight the importance of considering the context in which

536 decisions are made, and reveal how confident, effective decision making is subject to both

537 dynamic and static contextual influences. More detailed examination of each of these 
538

539

540

541

\section{2}

543

contexts is warranted and there is also a clear need to determine the extent to which the same contextual influences are common across different sports and other domains. Variability in regard to the perceived impact of situational pressure highlights the importance of identifying and measuring key individual difference variables in empirical research on decision making.

While challenging, this will lead to a more comprehensive understanding of decision making in sport that should yield theoretical as well as practical advances.

\section{Funding Sources}

This research did not receive any specific grant from funding agencies in the public, commercial, or not-for-profit sectors.

\section{References}

Abernethy, B., Gill, D. P., Parks, S. L., \& Packer, S. T. (2001). Expertise and the perception of kinematic and situational probability information. Perception, 30(2), 233-252. doi:10.1068/p2872

Bandura, A. (1977). Self-efficacy: Toward a unifying theory of behavioral change. Psychological Review, 84(2), 191-215. doi:10.1016/0146-6402(78)90002-4

Bar-Eli, M., \& Raab, M. (2009). Judgment and decision making in sport and exercise: A concise history and present and future perspectives. In D. Araujo, H. Ripoll \& M. Raab (Eds.), Perspectives on Cognition and Action in Sport (pp. 149-156). Portland, OR: Nova Science Publishers.

Barton, H., Jackson, R. C., \& Bishop, D. (2013). Knowledge of player tendencies: The effect on anticipation skill and susceptibility to deception. Journal of Sport \& Exercise Psychology, 35, S18.

Braun, V., \& Clarke, V. (2006). Using thematic analysis in psychology. Qualitative Research in Psychology, 3(2), 77-101. doi:10.1191/1478088706qp063oa 
562

563

564

565

566

567

568

569

570

571

572

573

574

575

576

577

578

579

580

581

582

583

584

585

586

Buszard, T., Farrow, D., \& Kemp, J. (2013). Examining the influence of acute instructional approaches on the decision-making performance of experienced team field sport players. Journal of Sports Sciences, 31(3), 238-247. doi:10.1080/02640414.2012.731516

Byrne, K. A., Silasi-Mansat, C. D., \& Worthy, D. A. (2015). Who chokes under pressure? the big five personality traits and decision-making under pressure. Personality and Individual Differences, 74, 22-28. doi:10.1016/j.paid.2014.10.009

Carron, A. V., Colman, M. M., Wheeler, J., \& Stevens, D. (2002). Cohesion and performance in sport: A meta-analysis. Journal of Sport and Exercise Psychology, 24, 168-188.

Chase, W. G., \& Simon, H. A. (1973). The mind's eye in chess. In W. Chase (Ed.), Visual Information Processing (pp. 215-281). London, England: Academic Press.

Davids, K., \& Araújo, D. (2010). The concept of 'Organismic Asymmetry’ in sport science. Journal of Science and Medicine in Sport, 13(6), 633-640.

doi:10.1016/j.jsams.2010.05.002

Ericsson, K. A., \& Ward, P. (2007). Capturing the naturally occurring superior performance of experts in the laboratory toward a science of expert and exceptional performance.

Current Directions in Psychological Science, 16(6), 346-350. doi:10.1111/j.14678721.2007.00533.x

Eysenck, M. W., Derakshan, N., Santos, R., \& Calvo, M. G. (2007). Anxiety and cognitive performance: attentional control theory. Emotion, 7(2), 336-353. doi:10.1037/15283542.7.2.336

Gray, R. (2002a). Behavior of college baseball players in a virtual batting task. Journal of Experimental Psychology: Human Perception and Performance, 28(5), 1131-1148. doi:10.1037/0096-1523.28.5.1131

Gray, R. (2002b). "Markov at the bat": a model of cognitive processing in baseball batters. Psychological Science, 13(6), 542-547. doi:10.1111/1467-9280.00495 
587

588

589

590

591

592

593

594

595

596

597

598

599

600

601

602

603

604

605

606

607

608

609

610

Hays, K., Maynard, I., Thomas, O., \& Bawden, M. (2007). Sources and types of confidence identified by world class sport performers. Journal of Applied Sport Psychology, 19(4), 434-456. doi:10.1080/10413200701599173

Hepler, T. J., \& Feltz, D. L. (2012). Take the first heuristic, self-efficacy, and decisionmaking in sport. Journal of Experimental Psychology: Applied, 18(2), 154-161. doi:10.1037/a0027807

Hoffman, R. R., Shadbolt, N. R., Burton, A. M., \& Klein, G. (1995). Eliciting knowledge from experts: A methodological analysis. Organizational Behavior and Human Decision Processes, 62(2), 129-158. doi:10.1006/obhd.1995.1039

Jackson, R. C., Kinrade, N. P., Hicks, T., \& Wills, R. (2013). Individual propensity for reinvestment: Field-based evidence for the predictive validity of three scales. International Journal of Sport Psychology, 44, 331-350. DOI: 10.7352/IJSP2013.44.331

Johnson, J. G., \& Raab, M. (2003). Take the first: Option-generation and resulting choices. Organizational Behavior and Human Decision Processes, 91(2), 215-229. doi:10.1016/S0749-5978(03)00027-X

Jones, G., Swain, A., \& Cale, A. (1991). Gender differences in precompetition temporal patterning and antecedents of anxiety and self-confidence. Journal of Sport \& Exercise Psychology, 13(1), 1-15. doi:10.1123/jsep.13.1.1

Kinrade, N. P., Jackson, R. C., \& Ashford, K. J. (2015). Reinvestment, task complexity and decision making under pressure in basketball. Psychology of Sport and Exercise, 20, 1119. doi:10.1016/j.psychsport.2015.03.007

Lausic, D., Tenebaum, G., Eccles, D., Jeong, A., \& Johnson, T. (2009). Intrateam communication and performance in doubles tennis. Research Quarterly for Exercise and Sport, 80(2), 281-290. doi:10.5641/027013609X13087704028598 
611 LeCouteur, A., \& Feo, R. (2011). Real-time communication during play: Analysis of team-

612 mates' talk and interaction. Psychology of Sport and Exercise, 12(2), 124-134.

613 doi:10.1016/j.psychsport.2010.07.003

614 Lenzen, B., Theunissen, C., \& Cloes, M. (2009). Situated analysis of team handball players'

615 decisions: An exploratory study. Journal of Teaching in Physical Education, 28(1), 54-

$616 \quad$ 74. doi:10.1123/jtpe.28.1.54

617 Loffing, F., Stern, R., \& Hagemann, N. (2015). Pattern-induced expectation bias in visual

618 anticipation of action outcomes. Acta Psychologica, 161, 45-53.

619 doi:10.1016/j.actpsy.2015.08.007

620 Macquet, A. (2009). Recognition within the decision-making process: A case study of expert 621 volleyball players. Journal of Applied Sport Psychology, 21(1), 64-79.

622 doi:10.1080/10413200802575759

623 Macquet, A., \& Fleurance, P. (2007). Naturalistic decision-making in expert badminton 624 players. Ergonomics, 50(9), 1433-1450. doi:10.1080/00140130701393452

625 Macquet, A., \& Kragba, K. (2015). What makes basketball players continue with the planned 626 play or change it? A case study of the relationships between sense-making and decision627 628 making. Cognition, Technology \& Work, 17(3), 345-353. doi:10.1007/s10111-015-0332-

629 McRobert, A. P., Ward, P., Eccles, D. W., \& Williams, A. M. (2011). The effect of 630 manipulating context-specific information on perceptual-cognitive processes during a 631 simulated anticipation task. British Journal of Psychology, 102(3), 519-534.

632 doi:10.1111/j.2044-8295.2010.02013.x

633 Murphy, C. P., Jackson, R. C., Cooke, K., Roca, A. Benguigui, N. \& Williams, A. M. (2016).

634 Contextual information and perceptual-cognitive expertise in a dynamic, temporally- 
constrained task. Journal of Experimental Psychology: Applied, 22(4), 455-470.

636 doi:10.1037/xap0000094

637 Oxford English Dictionary. Retrieved February $12^{\text {th }} 2018$, from

638 http://en.oxforddictionaries.com/definition/context

639 Paull, G., \& Glencross, D. (1997). Expert perception and decision making in baseball.

640 International Journal of Sport Psychology, 28(1), 35-36.

641 Raab, M., \& Laborde, S. (2011). When to blink and when to think: Preference for intuitive 642 decisions results in faster and better tactical choices. Research Quarterly for Exercise and Science, 82(1), 89-98. doi:10.1080/02701367.2011.10599725

644 Roca, A., Ford, P. R., McRobert, A. P., \& Williams, A. M. (2013). Perceptual-cognitive skills 645 and their interaction as a function of task constraints in soccer. Journal of Sport and $646 \quad$ Exercise Psychology, 35(2), 144-155. doi:10.1123/jsep.35.2.144

647 Rushall, B., \& Sherman, C. (1987). A definition and measurement of pressure in sport. 648 Journal of Applied Research in Coaching and Athletics, 2, 1-23.

649 Schläppi-Lienhard, O., \& Hossner, E. (2015). Decision making in beach volleyball defense:

650 Crucial factors derived from interviews with top-level experts. Psychology of Sport and $651 \quad$ Exercise, 16(1), 60-73. doi:10.1016/j.psychsport.2014.07.005

652 Smith, J. A. (1995). Semi-structured interviewing and qualitative analysis. In J. Smith, R.

653 Harré \& L. Van Langenhove (Eds.), Rethinking Methods in Psychology (pp. 8-26).

654 London, England: SAGE publications.

655 Starkes, J., \& Deakin, J. (1984). Perception in sport: A cognitive approach to skilled 656 performance. In W. F. Straub \& J. M. Williams (Eds.), Cognitive Sport Psychology (pp. 115-128). Lansing, MI: Sport Science Association. 
658

659

660

661

662

663

664

665

666

667

668

669

670

671

672

673

674

675

676

677

678

679

680

Tett, R. P., \& Guterman, H. A. (2000). Situation trait relevance, trait expression, and crosssituational consistency: Testing a principle of trait activation. Journal of Research in Personality, 34(4), 397-423. doi:10.1006/jrpe.2000.2292

Tracy, S. J. (2010). Qualitative quality: Eight "big-tent" criteria for excellent qualitative research. Qualitative Inquiry, 16(10), 837-851. doi:10.1177/1077800410383121

Travassos, B., Araújo, D., Davids, K., O'Hara, K., Leitão, J., \& Cortinhas, A. (2013). Expertise effects on decision-making in sport are constrained by requisite response behaviours - A meta-analysis. Psychology of Sport and Exercise, 14(2), 211-219. doi:10.1016/j.psychsport.2012.11.002

Vaeyens, R., Lenoir, M., Williams, A. M., \& Philippaerts, R. M. (2007). Mechanisms underpinning successful decision making in skilled youth soccer players: An analysis of visual search behaviors. Journal of Motor Behavior, 39(5), 395-408. doi:10.3200/JMBR.39.5.395-408

Vealey, R. S., Hayashi, S. W., Garner-Holman, M., \& Giacobbi, P. (1998). Sources of sportconfidence: Conceptualization and instrument development. Journal of Sport and Exercise Psychology, 20(1), 54-80. doi:10.1123/jsep.20.1.54

Verkoeijen, P. P., Rikers, R. M., Schmidt, H. G., Van De Wiel, M. W. J., \& Kooman, J. P. (2004). Case representation by medical experts, intermediates and novices for laboratory data presented with or without a clinical context. Medical Education, 38(6), 617-627. doi:10.1046/j.1365-2923.2004.01797.x

Williams, A. M. (2009). Perceiving the intentions of others: How do skilled performers make anticipation judgments? Progress in Brain Research, 174, 73-83. doi:10.1016/S00796123(09)01307-7 
681 Zardo, P., Collie, A., \& Livingstone, C. (2014). External factors affecting decision-making

682 and use of evidence in an Australian public health policy environment. Social Science \&

683 Medicine, 108, 120-127. doi:10.1016/j.socscimed.2014.02.046 
Contextual Factors Influencing Decision Making: Perceptions of Professional Soccer Players

Highlights

- Semi-structured interviews were conducted with eight professional soccer players

- Static and dynamic contextual themes were perceived to influence decision making

- Dynamic themes related to performance, score status, momentum, and communication

- Static themes related to match importance, perceived pressure, and preparation 